\title{
Preparation of $\mathrm{CuGaO}_{2}$ Thin Film by a Sol-Gel Method Using Two Kinds of Metal Source Combination
}

\author{
Takashi Ehara \\ Department of Human Culture, Faculty of Human Studies, Ishinomaki Senshu University, Ishinomaki, Japan \\ Email: ehara@isenshu-u.ac.jp
}

How to cite this paper: Ehara, T. (2018) Preparation of $\mathrm{CuGaO}_{2}$ Thin Film by a Sol-Gel Method Using Two Kinds of Metal Source Combination. Journal of Materials Science and Chemical Engineering, 6, 68-78.

https://doi.org/10.4236/msce.2018.68006

Received: July 25, 2018

Accepted: August 28, 2018

Published: August 31, 2018

Copyright $\odot 2018$ by author and Scientific Research Publishing Inc. This work is licensed under the Creative Commons Attribution International License (CC BY 4.0).

http://creativecommons.org/licenses/by/4.0/

\begin{abstract}
We prepare $\mathrm{CuGaO}_{2}$ thin films on $\mathrm{SiO}_{2}$ substrates by using the sol-gel spin-coating method with two combinations of $\mathrm{Cu}$ and a $\mathrm{Ga}$ source, $\mathrm{Cu}$ and $\mathrm{Ga}$ nitrate, or acetylacetonate. X-ray diffraction analysis reveals that the thin films prepared using nitrate sol that are annealed at a temperature of $850^{\circ} \mathrm{C}$ $950^{\circ} \mathrm{C}$ show both $c$-axis-orientated peaks, (006) and a non- $c$-axis-oriented peak (012) with similar intensity; little dependence of signal intensity on annealing temperature is also shown. The films are opaque in appearance at these annealing temperatures. Scanning electron microscope observation reveals that the opaque appearance is due to the texture or cracks on the surface of the films. In contrast, the films prepared using acetylacetonate show a (006) peak with higher signal intensity than the (012) peaks. The films show more transparent appearance than that of the films by nitrate. The highest conductivity of the film is $5.7 \times 10^{-4} \Omega^{-1} \cdot \mathrm{cm}^{-1}$, obtained in the films by nitrate annealed at $850^{\circ} \mathrm{C}$.
\end{abstract}

\section{Keywords}

Transparent Conductive Oxide, Delafossite, $\mathrm{CuGaO}_{2}$, Sol-Gel, Thin Films

\section{Introduction}

Transparent conductive oxide (TCO) thin films are widely used as a transparent electrode in opt-electric devices [1] [2]. However, most of the TCO thin films that have already been used in electric devices, such as indium tin oxide [3] or aluminum-doped zinc oxide [4], have n-type conductivity. Research on TCO with p-type conductivity is required for developing transparent electronics in order to form transparent pn-junctions. Cu-delafossite materials that are com- 
posed of copper and trivalent metal elements are known as p-type TCO candidates. One of the $\mathrm{Cu}$-delafossite materials, $\mathrm{CuAlO}_{2}$ shows intrinsic p-type conductivity because its valence band maximums are dominated by hybridization of oxygen orbitals with $3 \mathrm{~d}^{10}$ electrons in $\mathrm{Cu}^{+}$. The hybridization reduces contributions of oxygen orbitals to the valence band and makes the valence band dispersive, and p-type conductivity becomes available [5] [6]. Other Cu-delafossite materials, $\mathrm{CuGaO}_{2}$ has also been studied and recognized as a p-type TCO material with high transparency in thin-film form. $\mathrm{CuGaO}_{2}$ thin films have been prepared by various methods, such as pulsed laser deposition [7] [8], sputtering [9] [10], and the sol-gel method [11] [12] [13]. Among these methods, the sol-gel method is more convenient and less expensive than the other methods, and has a general advantage of superior uniformity. In the sol-gel preparation of $\mathrm{Cu}$-delafossite, two difficulties have been identified. One is the difficulty of the thermal treatment condition control required to form $\mathrm{Cu}$-delafossite, which contains $\mathrm{Cu}^{+}$, not $\mathrm{Cu}^{2+}$. The other is difficulty in the choice of metal source materials. Use of an inadequate combination of two metal source materials can be the expected course of the formation of binary ceramics by-product because of segregation of binary by-products due to the difference between copper and gallium in the film-formation process. The difference in the film-formation process can be thought to be suppressed by using metal source materials with the same anion or same complex ligand.

In the present work, $\mathrm{CuGaO}_{2}$ thin films were prepared by the sol-gel method using two combinations of a copper and gallium metal source that consist of the same counter anion or same complex ligand. One combination is copper nitrate and gallium nitrate that have the same anion, and the other is a combination of copper acetylacetonate and gallium acetylacetonate that have the same complex ligand.

\section{Experimental}

The raw materials for metal nitrate, copper nitrate and gallium nitrate were of analytical grade and purchased from Wako chemicals. Gallium nitrate was supplied as gallium nitrate $n$-hydrate $(n=7-9)$, with 8 adopted as the $n$ value for calculating molecular weight in the present work. Both copper nitrate trihydrate $(2.42 \mathrm{~g}, 0.01 \mathrm{~mol})$ and gallium nitrate n-hydrate $(4.00 \mathrm{~g}, 0.01 \mathrm{~mol})$ were separately dissolved into 2 -methoxyethanol $(25 \mathrm{~mL})$ by stirring for 12 hours at room temperature in air. Then, the nitrate sol was obtained by mixing two solutions and stirring for 12 hours at room temperature in air. The reagents for metal acetylacetonate, copper acetylacetonate and gallium acetylacetonate were of analytical grade and purchased from Aldrich. Copper acetylacetonate ( $2.62 \mathrm{~g}, 0.01$ $\mathrm{mol})$ and gallium acetylacetonate $(3.67 \mathrm{~g}, 0.01 \mathrm{~mol})$ were dissolved separately into a mixture of 2-methoxyethanol $(25 \mathrm{~mL})$ and 2-aminoethanol $(24.0 \mathrm{~g})$ by stirring for 72 hours at room temperature in air. The acetylacetonate sol was obtained by mixing two solutions and stirring for 12 hours at room temperature in 
air.

The sols were spin-coated onto $\mathrm{SiO}_{2}$ substrate at a spinning speed of 3000 $\mathrm{rpm}$. The coated films were first heated at $200^{\circ} \mathrm{C}$ for $10 \mathrm{~min}$, then, heated again at a higher temperature of $500^{\circ} \mathrm{C}$ for 20 min using hot-plate-type heating devices. We used high temperature, $500^{\circ} \mathrm{C}$, in the post-coating heat treatment under strictly temperature control in order to form $\mathrm{Cu}$-delafossite crystalline without $\mathrm{Cu}^{2+}[14]$. The spin-coating and subsequent heat-treatment procedures were repeated six times to obtain a film thickness of $0.2-0.3 \mu \mathrm{m}$. The prepared gel films were finally annealed at temperatures in the range of $750^{\circ} \mathrm{C}-1000^{\circ} \mathrm{C}$ for $10 \mathrm{~h}$ under nitrogen flow.

The structural properties of the films were studied by X-ray diffraction (XRD; D8 Discover, Bruker) analysis in the $\theta-2 \theta$ mode using $\mathrm{CuK} \alpha$ radiation. Transmission spectra were measured using a UV/Vis spectrophotometer (U-3000, Hitachi). The surface morphologies of the films were observed using scanning electron microscopy (SEM; JSN76380LV, JEOL). Conductivity of the films was measured using evaporated Au interdigital electrode with a gap of $0.5 \mathrm{~mm}$.

\section{Results and Discussion}

\subsection{Structural Properties}

Figure 1(a) shows the XRD patterns of the films prepared using the nitrate sol annealed at various temperatures. A broad signal at approximately $22^{\circ}$ and a peak at $21.6^{\circ}$ observed in the films annealed at $950^{\circ} \mathrm{C}-1000^{\circ} \mathrm{C}$ were ascribed to $\mathrm{SiO}_{2}$ glass and $\mathrm{SiO}_{2}$ crystalline, respectively. In the film annealed at $750^{\circ} \mathrm{C}$, a broad signal was observed at approximately $35.5^{\circ}-36.3^{\circ}$. It can be thought to be overlapping of three peaks, consisting of two $\mathrm{CuGaO}_{2}$ signals with orientations of (101) and (012) (PDF 00-041-0255) and a signal of CuO (200)(-111) (PDF 00-045-0937). The shape of the peak changed with increase in annealing temperature. At an annealing temperature of $800^{\circ} \mathrm{C}$, intensity of the $\mathrm{CuO}$ signal at $35.6^{\circ}$ decreased and a signal of $\mathrm{CuGaO}_{2}$ of (101) at $36.1^{\circ}$ and (012) at 36.5 increased. The intensity of the (101) signal decreased at an annealing temperature of $850^{\circ} \mathrm{C}$, then, it became a shoulder of the $(012)$ peak. At annealing temperatures of $900^{\circ} \mathrm{C}$ and $950^{\circ} \mathrm{C}$, the signal became one peak of (012) without a shoulder. However, the film annealed at $1000^{\circ} \mathrm{C}$ showed both (101) and (012) peaks again. At an annealing temperature of $850^{\circ} \mathrm{C}-950^{\circ} \mathrm{C}$, a $\mathrm{c}$-axis-oriented peak, (006), was also observed at $31.3^{\circ}$ in addition to (101) and (012). The relative intensity of these peaks, (006), (101) and (102), showed little dependency on annealing temperature at the annealing temperature region of $850^{\circ} \mathrm{C}-950^{\circ} \mathrm{C}$, and the (006) peak became weak at $1000^{\circ} \mathrm{C}$. Aside from these peaks, weak signals of (003), (104) and (105) have been observed at $15.5^{\circ}, 41.0^{\circ}$, and $44.2^{\circ}$, respectively.

Figure 1(b) shows the XRD patterns of the films prepared using the acetylacetonate sol annealed at various temperatures. The film annealed at $750^{\circ} \mathrm{C}$ displays no peaks, and the films annealed at $800^{\circ} \mathrm{C}-900^{\circ} \mathrm{C}$ show three peaks of (006), (101) and (012). Peak positions of (006) and (012) are consistent with that 


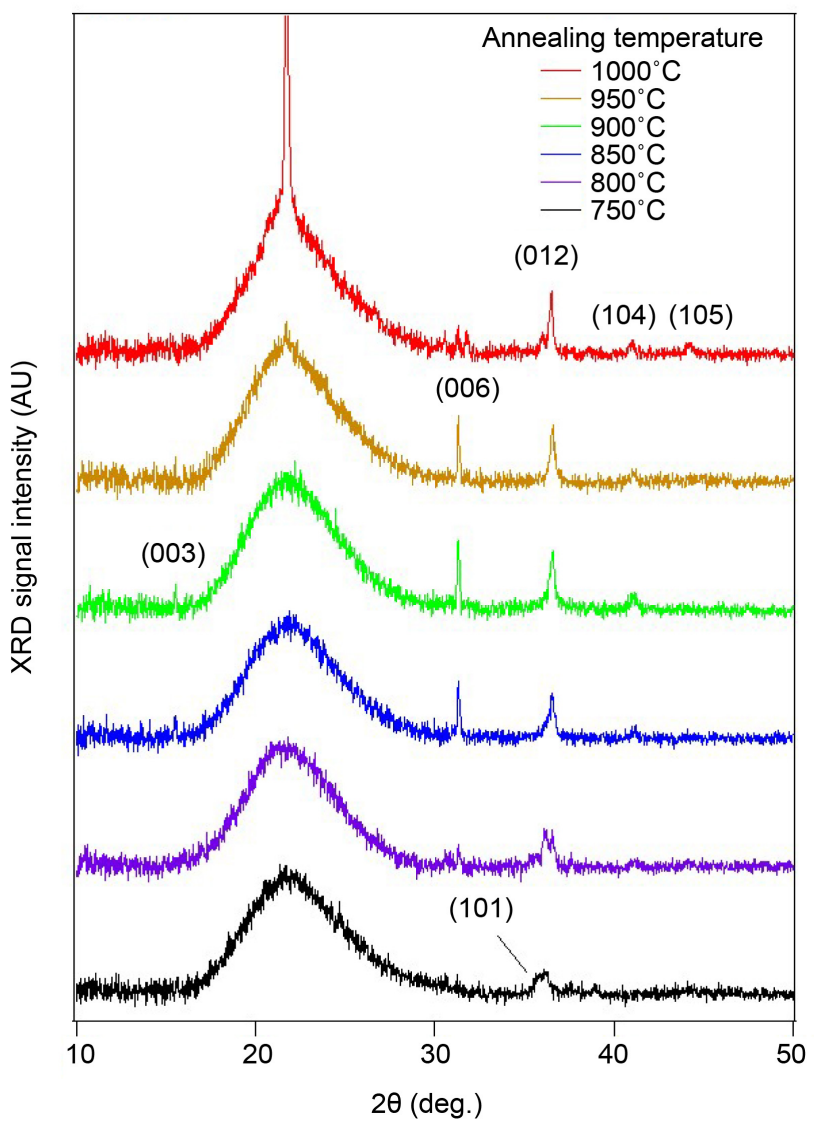

(a)

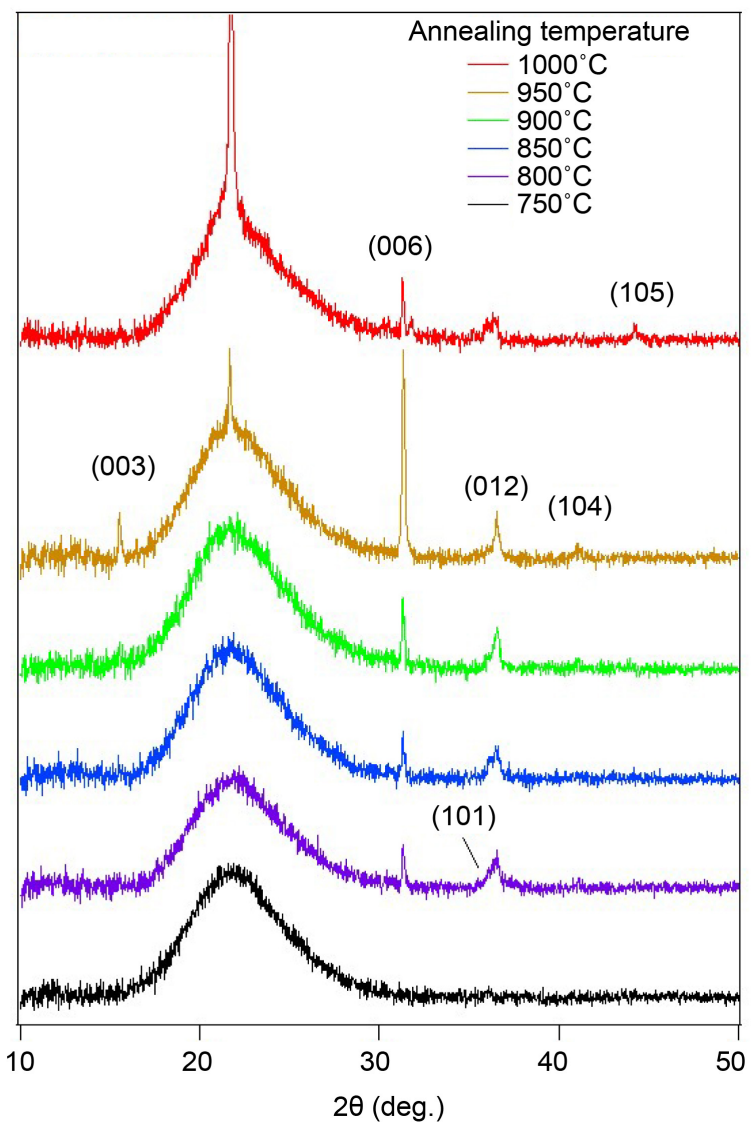

(b)

Figure 1. X-ray diffraction patterns of the thin films prepared by the sol-gel method using (a) metal nitrate and (b) metal acetylacetonate as a metal source. The films were annealed at $750^{\circ} \mathrm{C}-1000^{\circ} \mathrm{C}$ in $\mathrm{N}_{2}$ for $10 \mathrm{~h}$.

in the film prepared using nitrate sol shown in Figure 1(a). However, the signal of (101) was observed as a shoulder of the (012) peak in all films, while the signal of $\mathrm{CuO}$ was not observed. Unlike the films prepared using nitrate sol, the films annealed at temperatures higher than $800^{\circ} \mathrm{C}$ showed a (006) peak and the signal intensity of the peak showed dependency on annealing temperature. The signal intensity increased with annealing temperature from $800^{\circ} \mathrm{C}$ and the intensity became the highest at $950^{\circ} \mathrm{C}$, then decreased at $1000^{\circ} \mathrm{C}$. At $950^{\circ} \mathrm{C}$, a peak with orientation of (003), that is another $c$-axis-oriented peak, was observed at $15.5^{\circ}$. This result indicates that the film annealed at $950^{\circ} \mathrm{C}$ has a $c$-axis-oriented crystalline structure compared with other films in the present work. Other weak peaks, (104) and (105), were also observed, as well as in films prepared using nitrate sol.

In all the XRD patterns, signals of $\mathrm{Ga}_{2} \mathrm{O}_{3}$ were not observed and only a weak signal of $\mathrm{CuO}$ was observed as a shoulder of peaks in some of the films. The use of sols containing only the same anion or some complex ligand can be thought to have prevented the formation of by-products. As also observed by XRD measurements, the films with different raw materials had different structures. As a trend, structural properties of the films prepared using acetylacetonate had 
more significant annealing temperature dependence and more significant $c$-axis-oriented structure than the films prepared using nitrate sol.

\subsection{Transparency of the Films}

Figure 2(a) and Figure 2(b) shows an optical image of the $\mathrm{CuGaO}_{2}$ thin films prepared by the sol-gel method using nitrate sol and acetylacetonate sol, respectively. Each picture corresponds to annealing temperatures, $750^{\circ} \mathrm{C}, 800^{\circ} \mathrm{C}, 850^{\circ} \mathrm{C}$, $900^{\circ} \mathrm{C}, 950^{\circ} \mathrm{C}$ and $1000^{\circ} \mathrm{C}$, from left to right. As seen in the figure, films prepared from acetylacetonate show higher transparency than the films prepared using nitrate. In addition, the transparency of the films was preferable compared with that of $\mathrm{CuAlO}_{2}$ used in our previous works not only for the films prepared by the sol-gel method [14] [15] but also by sputtering [16]. The films prepared from nitrate sol showed relatively higher transparency at temperatures of $900^{\circ} \mathrm{C}$ or $950^{\circ} \mathrm{C}$; however, these films showed opaque appearance compared with the films prepared by acetylacetonate. Films prepared using acetylacetonate sol showed preferable transmittance at an annealing temperature range of $850^{\circ} \mathrm{C}-950^{\circ} \mathrm{C}$.

Transmission spectra of $\mathrm{CuGaO}_{2}$ thin films prepared using nitrate sol followed by annealing at $800^{\circ} \mathrm{C}, 900^{\circ} \mathrm{C}$ and $1000^{\circ} \mathrm{C}$ are shown in Figure $3(\mathrm{a})$. However, the figure does not display how the films annealed at $850^{\circ} \mathrm{C}$ and $950^{\circ} \mathrm{C}$ showed similar spectra as the film annealed at $900^{\circ} \mathrm{C}$. At a wavelength of 400 $\mathrm{nm}$, the films annealed at $800^{\circ} \mathrm{C}, 900^{\circ} \mathrm{C}$ and $1000^{\circ} \mathrm{C}$ showed transmissions of $36 \%, 67 \%$ and $56 \%$, respectively. Figure $3(\mathrm{~b})$ depicts the transmission spectra of $\mathrm{CuGaO}_{2}$ thin films prepared using acetylacetonate sol annealed at $800^{\circ} \mathrm{C}, 900^{\circ} \mathrm{C}$ and $1000^{\circ} \mathrm{C}$. The films show higher transparency than the films prepared by nitrate. At a wavelength of $400 \mathrm{~nm}$, the films annealed at $800^{\circ} \mathrm{C}, 900^{\circ} \mathrm{C}$ and $1000^{\circ} \mathrm{C}$ showed transmissions of $75 \%, 75 \%$ and $62 \%$, respectively. In addition, the films showed transmittance of more than $20 \%$ at a wavelength of $200 \mathrm{~nm}$. These results indicate that the origin of the metal affects the optical properties of the films. Similar transmittance spectra to that observed in the sample annealed at

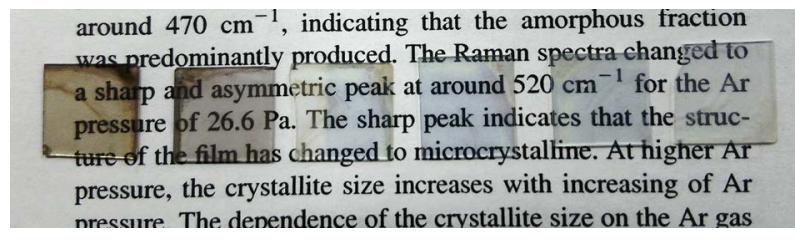

(a)

prepared at various Ar gas pressures ranging from 13.3 to $79.8 \mathrm{~Pa}(0.1-0.6 \mathrm{Torr})$ and the spectrum of $a$-Si for comparison. The $x$-ray diffraction measurements verified the formation of microcrystallites at the Ar gas pressures higher than 26.6 Pa. The crystallite size determined by Sherrer's formula is nrenared at Ar pressure of $13.3 \mathrm{~Pa}$ has a broad peak at

(b)

Figure 2. Optical images of the $\mathrm{CuGaO}_{2}$ thin films prepared using (a) metal nitrate, (b) metal acetylacetonate, annealed in $\mathrm{N}_{2}$. Left to right, the films were annealed at $750^{\circ} \mathrm{C}, 800^{\circ} \mathrm{C}$, $850^{\circ} \mathrm{C}, 900^{\circ} \mathrm{C}, 950^{\circ} \mathrm{C}$ and $1000^{\circ} \mathrm{C}$. 


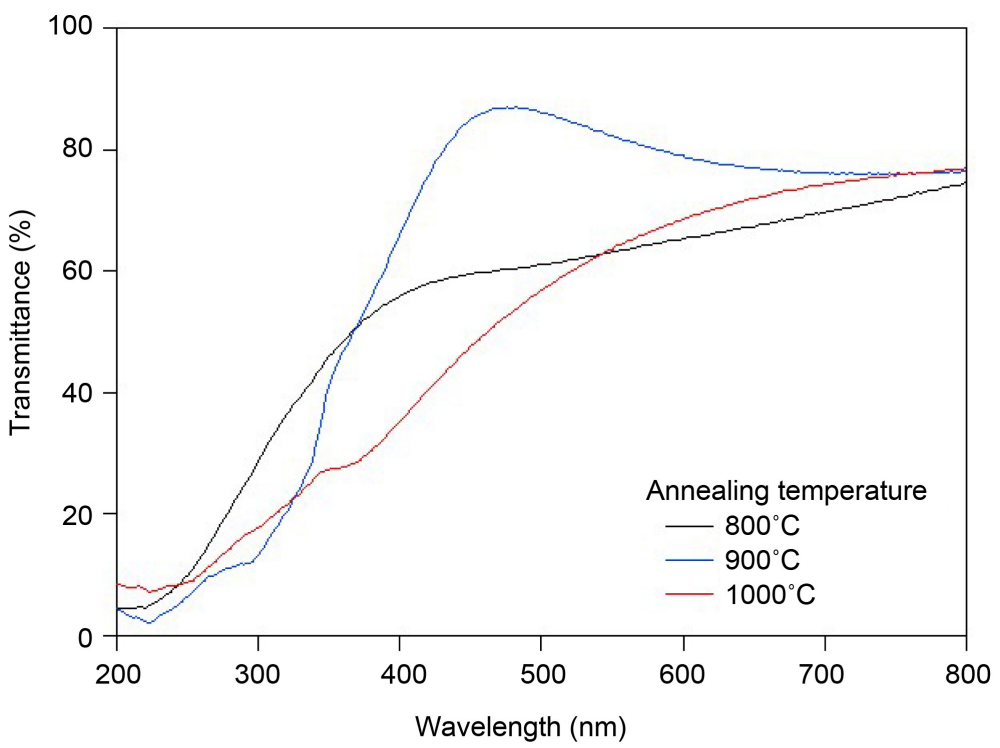

(a)

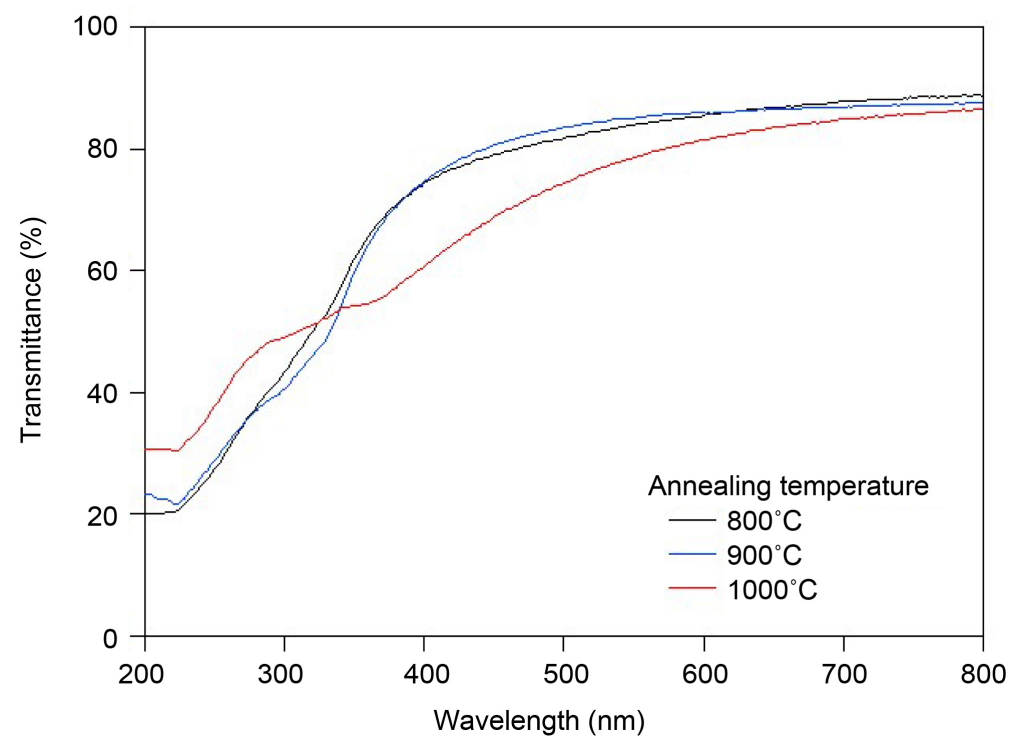

(b)

Figure 3. Transmission spectra of the $\mathrm{CuGaO}_{2}$ thin films prepared using (a) metal nitrate and (b) metal acetylacetonate.

$900^{\circ} \mathrm{C}$ was also observed in the films annealed at $850^{\circ} \mathrm{C}$ and $950^{\circ} \mathrm{C}$, although the structural properties changed depending on the annealing temperature, as observed in XRD.

Figure 4(a) and Figure 4(b) show Tauc plots (plot of $(\alpha h v)^{2}$ against photon energy) of the films prepared from nitrate and acetylacetonate annealed at $800^{\circ} \mathrm{C}, 900^{\circ} \mathrm{C}$, and $1000^{\circ} \mathrm{C}$, respectively. In all the films, an optical bandgap of greater than $3.1 \mathrm{eV}$ was obtained. In the films prepared using both the nitrate and the acetylacetonate sols annealed at $1000^{\circ} \mathrm{C}$, absorption at $2.5-3.5 \mathrm{eV}$ was observed. The absorption is thought to be due to the localized state that was caused by destruction of crystalline. 


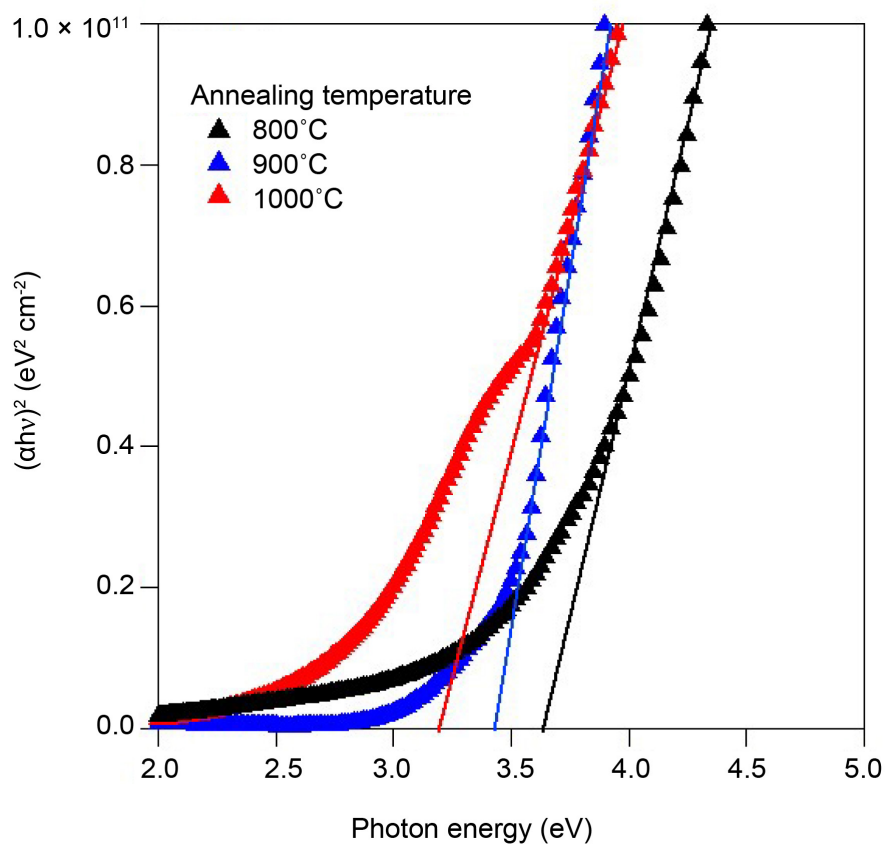

(a)

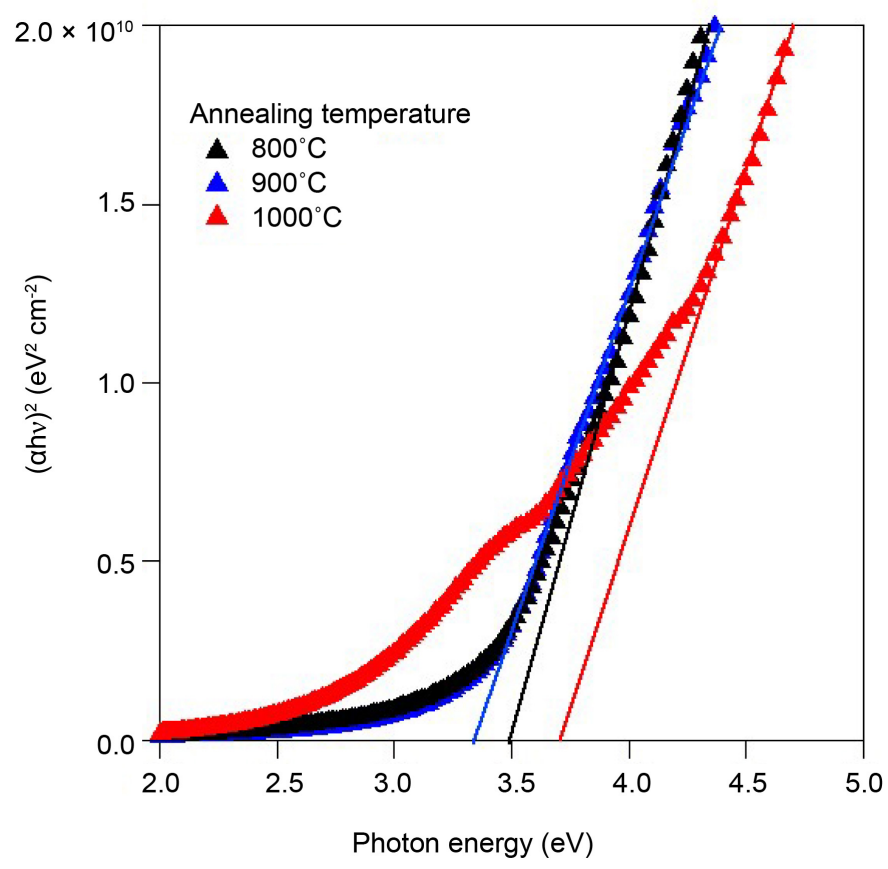

(b)

Figure 4. Tauc plots (plot of $(\alpha h v)^{2}$ against photon energy) for determining the optical bandgap of the film prepared using (a) nitrate and (b) acetylacetonate annealed at $800^{\circ} \mathrm{C}, 900^{\circ} \mathrm{C}$ and $1000^{\circ} \mathrm{C}$.

\subsection{Surface Morphology}

Figures 5(a)-(c) shows SEM images of $\mathrm{CuGaO}_{2}$ thin films prepared using metal nitrate annealed at $800^{\circ} \mathrm{C}, 900^{\circ} \mathrm{C}$ and $1000^{\circ} \mathrm{C}$, respectively. The film annealed at $800^{\circ} \mathrm{C}$ shows formation of crystalline grains with approximately $0.5 \mu \mathrm{m}$ diameters 


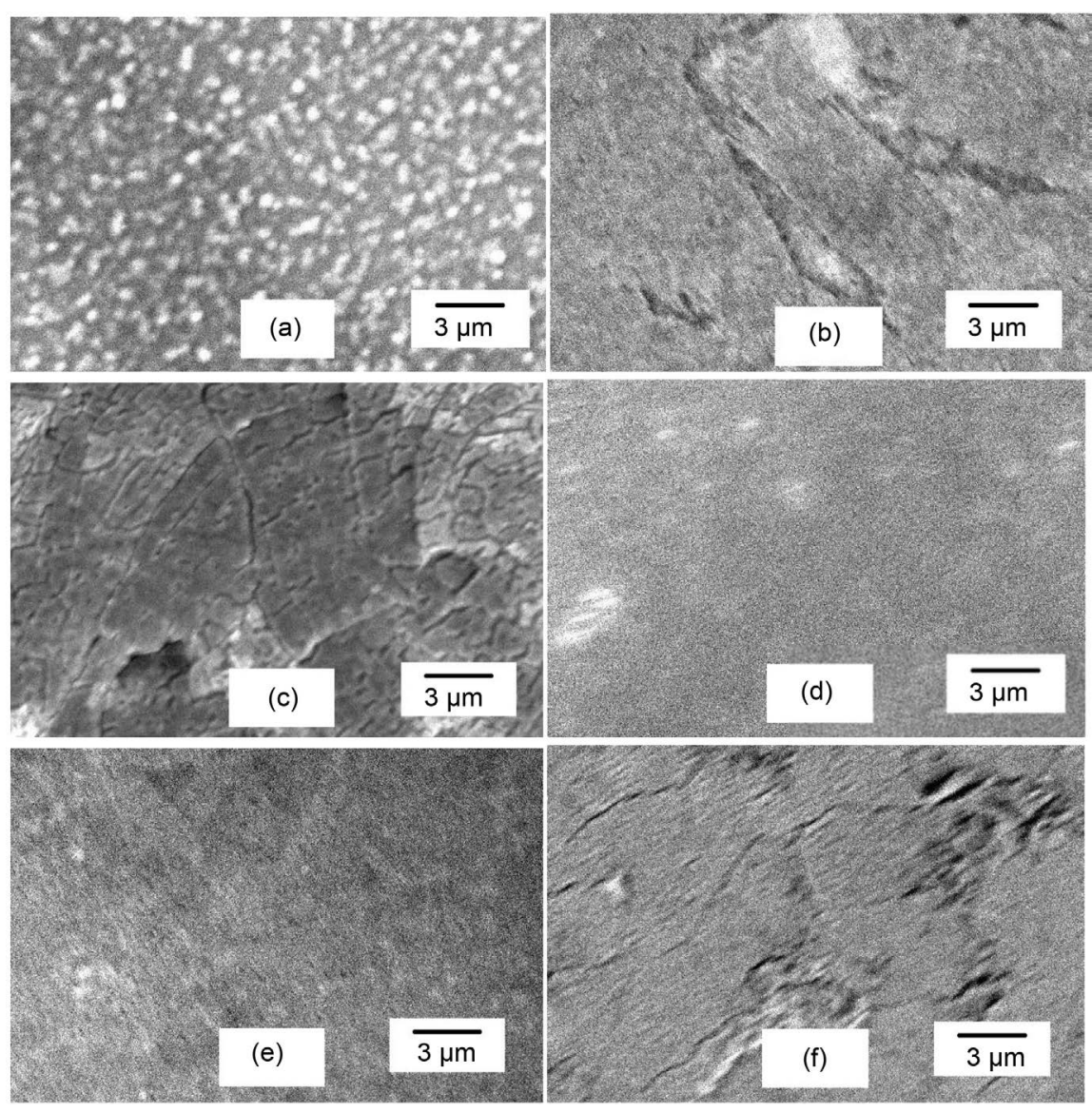

Figure 5. Scanning electron microscope images of $\mathrm{CuGaO}_{2}$ thin films prepared using nitrate (a) annealed at $800^{\circ} \mathrm{C}$, (b) $900^{\circ} \mathrm{C}$ and (c) $1000^{\circ} \mathrm{C}$, or acetylacetonate annealed at (d) $800^{\circ} \mathrm{C}$, (e) $900^{\circ} \mathrm{C}$ and (f) $1000^{\circ} \mathrm{C}$.

on the surface. At an annealing temperature of $900^{\circ} \mathrm{C}$, textures with a scale of 5 $10 \mu \mathrm{m}$ were observed and crystalline grains were not observed. For the film annealed at $1000^{\circ} \mathrm{C}, 1-2 \mu \mathrm{m}$ square-structured grains were observed with cracks in the boundary of these grains. These results indicate that the surface morphology of the $\mathrm{CuGaO}_{2}$ films prepared using nitrate sol changes drastically depending on the annealing temperature. The crystalline grains observed at an annealing temperature of $800^{\circ} \mathrm{C}$ can be thought to become larger with increase in annealing temperature. Then, the surface becomes one with the texture or larger crystalline grains.

Figures 5(d)-(e) shows SEM images of $\mathrm{CuGaO}_{2}$ thin films prepared using metal acetylacetonate annealed at $800^{\circ} \mathrm{C}, 900^{\circ} \mathrm{C}$ and $1000^{\circ} \mathrm{C}$, respectively. The films prepared using acetylacetonate show a relatively smooth surface compared with that in the films prepared by nitrate. At annealing temperatures of $800^{\circ} \mathrm{C}$ $900^{\circ} \mathrm{C}$, formation of crystalline grain is not well observed at the surface of the films. As shown in Figure 2, the films prepared using nitrate showed more opaque appearance compared with the films prepared by acetylacetonate. The difference in the surface morphology can be the cause of the difference in the appearance of the films depending on the metal source materials. 


\subsection{Conductivity of the Films}

Figure 6 depicts the annealing temperature variation of conductivity of the $\mathrm{Cu}$ $\mathrm{GaO}_{2}$ thin films prepared by the nitrate sol and acetylacetonate sol. The films show p-type conductivity confirmed by Seebeck measurement. Conductivity of the films prepared at an annealing temperature of $1000^{\circ} \mathrm{C}$ and the film prepared by nitrate annealed at $950^{\circ} \mathrm{C}$ were too low to be measured. For the films prepared using nitrate sol, the film annealed at $750^{\circ} \mathrm{C}$ showed conductivity of $1.4 \times$ $10^{-7} \Omega^{-1} \cdot \mathrm{cm}^{-1}$ and increase with annealing temperature until $850^{\circ} \mathrm{C}$, with the highest conductivity being $5.7 \times 10^{-4} \Omega^{-1} \cdot \mathrm{cm}^{-1}$. The conductivity was increased by more than three orders of magnitude. At higher temperature than $950^{\circ} \mathrm{C}$, the conductivity decreased by more than six orders of magnitude compared with that in $850^{\circ} \mathrm{C}$.

In the films prepared using the acetylacetonate sol, the film showed conductivity of $3.8 \times 10^{-6} \Omega^{-1} \cdot \mathrm{cm}^{-1}$ at an annealing temperature of $750^{\circ} \mathrm{C}$, which was higher than that in the film prepared by the nitrate sol at the same annealing temperature. The conductivity of the film increased with annealing temperature as well as in the films prepared by the nitrate sol; however, the highest conductivity obtained by acetylacetonate film was $1.6 \times 10^{-5} \Omega^{-1} \cdot \mathrm{cm}^{-1}$ at the annealing temperature of $850^{\circ} \mathrm{C}$, which is a lower value than that in the film prepared using nitrate. The conductivity increased by less than one order from the annealing temperatures of $750^{\circ} \mathrm{C}-850^{\circ} \mathrm{C}$. In addition, decreasing conductivity at higher temperature was less than two orders from $850^{\circ} \mathrm{C}$ to $950^{\circ} \mathrm{C}$.

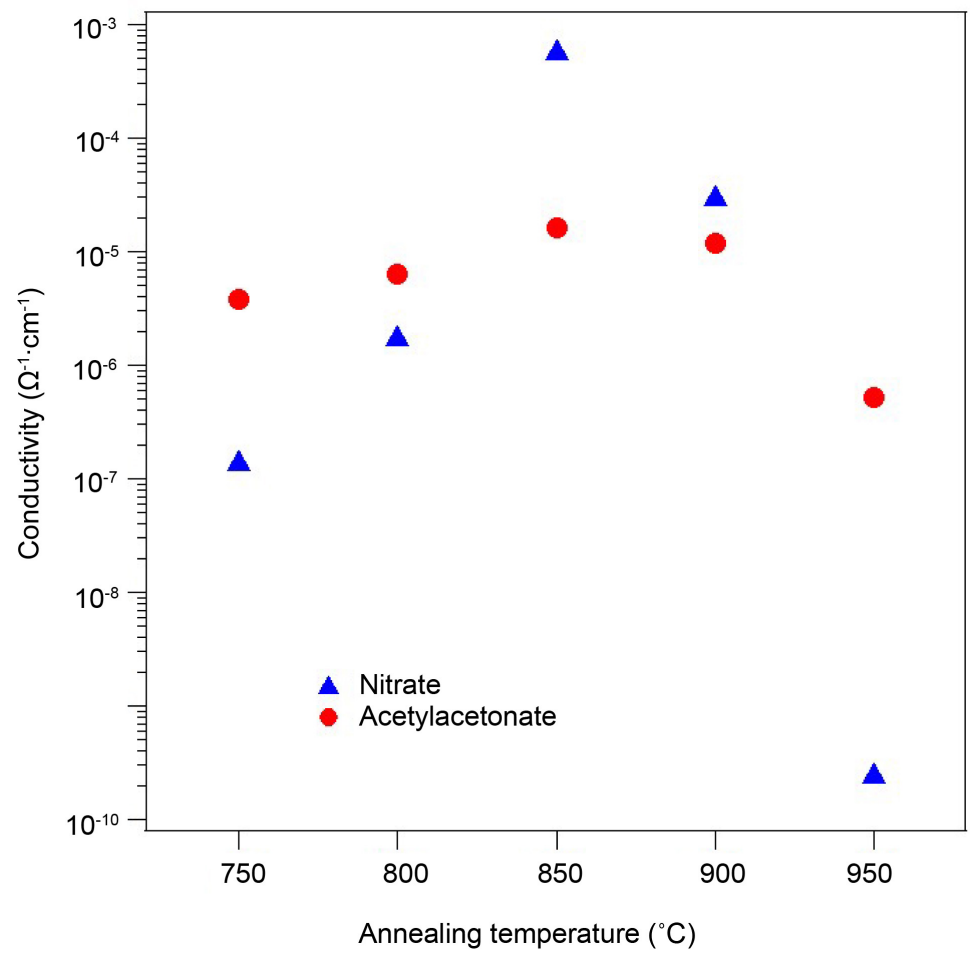

Figure 6. Conductivity of the $\mathrm{CuGaO}_{2}$ thin films prepared by the sol-gel method. 


\section{Conclusion}

$\mathrm{CuGaO}_{2}$ thin films were prepared by the sol-gel method using two kinds of combination of metal source materials, $\mathrm{Cu}$ and $\mathrm{Al}$ nitrate, and acetylacetonate. The films showed dependence of the structural, optical and electrical properties not only on the annealing temperature, but also on the metal source materials. In the case of the films prepared by the nitrate sol, XRD signal intensity did not show significant dependency on annealing temperature; however, surface morphology and conductivity showed significant dependency on annealing temperature. In contrast, in the case of the films prepared using the acetylacetonate sol, XRD signal intensity showed dependence on the annealing temperature. However, surface morphology and conductivity showed independency on the annealing temperature. The films prepared using acetylacetonate showed preferable transparency compared with the films prepared using nitrate. Transmittance of the films at wavelengths longer than $400 \mathrm{~nm}$ was more than $75 \%$ at annealing temperatures of $800^{\circ} \mathrm{C}-900^{\circ} \mathrm{C}$. The highest conductivity of $5.7 \times 10^{-4} \Omega^{-1} \cdot \mathrm{cm}^{-1}$ was obtained by the film prepared by the nitrate sol followed by annealing at $850^{\circ} \mathrm{C}$. Because of the use of metal source materials with the same anion or same complex ligand and strict control of heat treatment, by-products were not observed at an annealing temperature higher than $850^{\circ} \mathrm{C}$.

\section{Acknowledgements}

This work has been financially supported by Kyoso Kenkyu Josei in 2017 of Ishinomaki Senshu University.

\section{Conflicts of Interest}

The author declares no conflicts of interest regarding the publication of this paper.

\section{References}

[1] Xu, G., Liu, Z., Ma, J., Liu, B., Ho, S.T., Wang, L., Zhu, P., Marks, T.J., Luo, J. and Jen, A.K.Y. (2005) Organic Electro-Optic Modulator Using Transparent Conducting Oxides as Electrodes. Optics Express, 13, 7380-7385.

https://doi.org/10.1364/OPEX.13.007380

[2] Ellmer, K. (2012) Past Achievements and Future Challenges in the Development of Optically Transparent Electrodes. Nature Photonics, 6, 809-817.

https://doi.org/10.1038/nphoton.2012.282

[3] Kim, H., Gilmore, C.M., Piqué, A., Horwitz, J.S., Mattoussi, H., Murata, H., Kafafi, J.H. and Chrisey, D.B. (1999) Electrical, Optical, and Structural Properties of Indium-Tin-Oxide Thin Films for Organic Light-Emitting Devices. Journal of Applied Physics, 86, 6451-6461. https://doi.org/10.1063/1.371708

[4] Tsuji, T. and Hirohashi, M. (2000) Influence of Oxygen Partial Pressure on Transparency and Conductivity of RF Sputtered Al-Doped ZnO Thin Films. Applied Surface Science, 157, 47-51. https://doi.org/10.1016/S0169-4332(99)00517-6

[5] Benko, F.A. and Koffyberg, F.P. (1984) Opto-Electronic Properties of $\mathrm{CuAlO}_{2}$. Journal of Physics and Chemistry of Solids, 45, 57-59. 
https://doi.org/10.1016/0022-3697(84)90101-X

[6] Kawazoe, H., Yasukawa, M., Hyodou, H., Kurita, M., Yanagi, H. and Hosono, H. (1997) P-Type Electrical Conduction in Transparent Thin Films of $\mathrm{CuAlO}_{2}$. Nature, 389, 939-942. https://doi.org/10.1038/40087

[7] Ueda, K., Hase, T., Yanagi, H., Kawazoe, H., Hosono, H., Ohta, H., Orita, M. and Hirano, M. (2000) Epitaxial Growth of Transparent P-Type Conducting $\mathrm{CuGaO}_{2}$ Thin Films on Sapphire (001) Substrates by Pulsed Laser Deposition. Journal of Applied Physics, 89, 1790-1793. https://doi.org/10.1063/1.1337587

[8] Mine, T., Yanagi, H., Nomura, K., Kamiya, T., Hirano, M. and Hosono, H. (2008) Control of Carrier Concentration and Surface Flattening of $\mathrm{CuGaO}_{2}$ Epitaxial Films for a P-Channel Transparent Transistor. Thin Solid Films, 516, 5790-5794. https://doi.org/10.1016/j.tsf.2007.10.072

[9] Yanagi, H., Kawazoe, H., Kudo, A., Yasukawa, M. and Hosono, H. (2000) Chemical Design and Thin Film Preparation of P-Type Conductive Transparent Osxides. Journal of Electroceramics, 4, 407-414. https://doi.org/10.1023/A:1009959920435

[10] Bakar, M.H.A., Li, L.M., Mohamad, K.A., Sulaiman, S., Salleh, S. and Alias, A. (2015) Fabrication and Characterization of 6,13-Bis(triisopropylsilylethynyl)Pentacene Active Semiconductor Thin Films Prepared by Flow-Coating Method. AIP Conference Proceedings, 1674, Article ID: 020003. https://doi.org/10.1063/1.4928820

[11] Alias, A., Sakamoto, M., Kimura, T. and Uesugi, K. (2012) Temperature Dependence of $\mathrm{CuGaO}_{2}$ Films Fabricated by Sol-Gel Method. Japanese Journal of Applied Physics, 51, Article ID: 035503. https://doi.org/10.7567/JJAP.51.035503

[12] Alias, A., Sakamoto, M., Kimura, T. and Uesugi, K. (2011) Characterization of Cu$\mathrm{GaO}_{2}$ Films Prepared by Sol-Gel Methods. Physica Status Solidi C, 9, 198-201. https://doi.org/10.1002/pssc.201100290

[13] Elsayed, I.A., Fahmy, T., El-Tantawy, F., Farooq, W.A. and Yakuphanoglu, F. (2014) Electrical and Photoresponse Properties of $p-\mathrm{CuGaO}_{2}$-on- $p$-Si/Al Photodiode. Journal of Nanoelectronics and Optoelectronics, 9, 584-589. https://doi.org/10.1166/jno.2014.1637

[14] Ehara, T., Abe, H., Iizaka, R., Abe, K. and Sato, T. (2017) Crystalline Orientation Control in Sol-Gel Preparation of $\mathrm{CuAlO}_{2}$ Thin Films. Journal of Sol-Gel Science and Technology, 82, 363-369. https://doi.org/10.1007/s10971-017-4306-2

[15] Ohashi, M., Iida, Y. and Morikawa, H. (2002) Preparation of $\mathrm{CuAlO}_{2}$ Films by Wet Chemical Synthesis. Journal of the American Ceramic Society, 85, 270-272. https://doi.org/10.1111/j.1151-2916.2002.tb00080.x

[16] Ehara, T., Iizaka, R., Abe, M., Abe, K. and Sato, T. (2017) Preparation of $\mathrm{CuAlO}_{2}$ Thin Films by Radio Frequency Magnetron Sputtering and the Effect of Sputtering on the Target Surface. Journal of Ceramic Science and Technology, 8, 7-12. https://doi.org/10.4416/JCST2016-00066 